\title{
History Dependence of the Microstructure on Time- Dependent Deformation During In-Situ Cooling of a Nickel-Based Single-Crystal Superalloy
}

\author{
CHINNAPAT PANWISAWAS @D, NEIL D'SOUZA, DAVID M. COLLINS, \\ AYAN BHOWMIK, and BRYAN ROEBUCK
}

Time-dependent plastic deformation through stress relaxation and creep deformation during in-situ cooling of the as-cast single-crystal superalloy CMSX- $4{ }^{\circledR}$ has been studied via neutron diffraction, transmission electron microscopy, electro-thermal miniature testing, and analytical modeling across two temperature regimes. Between $1000{ }^{\circ} \mathrm{C}$ and $900{ }^{\circ} \mathrm{C}$, stress relaxation prevails and gives rise to softening as evidenced by a decreased dislocation density and the presence of long segment stacking faults in $\gamma$ phase. Lattice strains decrease in both the $\gamma$ matrix and $\gamma^{\prime}$ precipitate phases. A constitutive viscoplastic law derived from in-situ isothermal relaxation test underestimates the equivalent plastic strain in the prediction of the stress and strain evolution during cooling in this case. It is thereby shown that the history dependence of the microstructure needs to be taken into account while deriving a constitutive law and which becomes even more relevant at high temperatures approaching the solvus. Higher temperature cooling experiments have also been carried out between $1300{ }^{\circ} \mathrm{C}$ and $1150{ }^{\circ} \mathrm{C}$ to measure the evolution of stress and plastic strain close to the $\gamma^{\prime}$ solvus temperature. In-situ cooling of samples using ETMT shows that creep dominates during high-temperature deformation between $1300{ }^{\circ} \mathrm{C}$ and $1220{ }^{\circ} \mathrm{C}$, but below a threshold temperature, typically $1220^{\circ} \mathrm{C}$ work hardening begins to prevail from increasing $\gamma^{\prime}$ fraction and resulting in a rapid increase in stress. The history dependence of prior accumulated deformation is also confirmed in the flow stress measurements using a single sample while cooling. The saturation stresses in the flow stress experiments show very good agreement with the stresses measured in the cooling experiments when viscoplastic deformation is dominant. This study demonstrates that experimentation during high-temperature deformation as well as the history dependence of the microstructure during cooling plays a key role in deriving an accurate viscoplastic constitutive law for the thermo-mechanical process during cooling from solidification.

https://doi.org/10.1007/s11661-018-4703-3

(c) The Author(s) 2018

CHINNAPAT PANWISAWAS is with the School of Metallurgy and Materials, University of Birmingham, Birmingham B15 2TT, UK and also with the Department of Materials, University of Oxford, Parks Road, Oxford OX1 3PH, UK. Contact e-mail: chinnapat.panwisawas@materials.ox.ac.uk NEIL D'SOUZA is with Rolls-Royce ple, PO Box 31, Derby DE24 8BJ, UK. DAVID M. COLLINS is with the School of Metallurgy and Materials, University of Birmingham, Birmingham B15 2TT, UK. AYAN BHOWMIK is with the Department of Materials, Imperial College London, Exhibition Road, London SW7 2AZ, UK and also with the Rolls-Royce@NTU Corporate Lab, Nanyang Technological University, Singapore 637460, Singapore. BRYAN ROEBUCK is with the National Physical Laboratory, Teddington, Middlesex TW11 0LW, UK.

Manuscript submitted March 2, 2018.

Article published online May 31, 2018

\section{INTRODUCTION}

HIGH-TEMPERATURE deformation during cooling from solidification in single-crystal superalloys is significant for rationalization and prediction of the stress and strain development in turbine blade investment casting. Thermo-mechanical deformation following solidification progressively occurs in the solid metal as a function of local cooling rate and specific geometrical features.$^{[1,2]}$ This gives rise to localized stress evolution in the casting. In order to capture the thermo-mechanical response induced during cooling from solidification, the time-dependent deformation at high temperature is studied. Traditionally, isothermal stress-strain curves under constant strain rate or constant stress and temperature describe the material behavior during processing and in-service conditions. ${ }^{[3-7]}$ While non-isothermal creep properties under such high-temperature/lowstress conditions have been studied extensively in nickelbased single-crystal superalloys, e.g., MC2 ${ }^{[8-10]} \mathrm{CMSX}-4^{[11]}$ and MC-NG, ${ }^{[12,13]}$ such testing typically represented the 
in-service conditions for creep life assessment at temperatures up to $1200{ }^{\circ} \mathrm{C}$ but neglect the history dependence of the microstructure, i.e., the role of accumulated deformation at a higher temperature on subsequent deformation at the lower temperature. ${ }^{[14,15]}$ Including this aspect is critical for an accurate prediction of thermo-mechanical processes during investment casting. ${ }^{[16]}$

Micro-mechanisms such as creep and stress relaxation constitute high-temperature deformation relevant to cooling from solidification. ${ }^{[17,18]}$ In-situ creep and stress relaxation experiments under relevant stress and temperature conditions to the investment casting process have been investigated. $^{[19]}$ The emphasis is to obtain better understanding of the deformation behavior and the role of microstructure in developing a constitutive law to quantify the evolution of stress and strain during cooling. Both viscoplastic as well as (less computationally expensive) elastoplastic isotropic hardening models can be considered to calculate the evolution of stress and strain. ${ }^{[20]}$ However, the key question regarding the critical temperature range when viscoplasticity dominates just at/below the solidus temperature remains ambiguous. ${ }^{[16]}$ To rationalize the underlying micro-mechanisms controlling such deformation requires using in-situ and post-mortem investigations. Therefore, the temporal measurement of deformation via neutron diffraction and ETMT as well as post-deformation TEM characterization investigations provide a complementary approach that could offer sufficient information to elucidate the governing micro-mechanisms. This can be ultimately used to construct high-temperature databases for numerical simulations and prediction of stress and strain evolution during casting.

The aim in this study is therefore two-fold. First, in-situ neutron diffraction has been used to evaluate the evolution of the lattice (elastic) strains in the $\gamma$ matrix and $\gamma^{\prime}$ precipitates when subjecting the CMSX-4 single-crystal nickel-based superalloy samples to the stresses at temperatures well below the $\gamma^{\prime}$ solvus during cooling. In-situ isothermal stress relaxation experiments have been used to derive a viscoplastic law, which was then used to predict the mechanical response during cooling. The macroscopic stresses and strains that develop in an incremental temperature interval during cooling have been calculated via a numerical modeling approach. Second, the evolution of stress and strain was measured close to the solvus temperature using an electro-thermal miniature (ETMT) test system. This approach is used due to the limited capability of the furnace for neutron diffraction under such in-situ cooling conditions at high temperatures.

\section{METHOD}

\section{A. In-Situ Cooling from $1000{ }^{\circ} \mathrm{C}$ to $950^{\circ} \mathrm{C}$ Using Neutron Diffraction and TEM}

*CMSX-4 uniaxial as-cast tensile specimens were

*CMSX-4 is a registered trademark of Cannon-Muskegon Corporation.

manufactured and directionally solidified as single crystals via the investment casting route, following
D'Souza et al. ${ }^{[17]}$ and machined to have diameter 5.85 $\mathrm{mm}$ and gauge length $29 \mathrm{~mm}$. The specimens were seeded to ensure that the axial orientation of the specimens was within $5 \mathrm{deg}$ from $\langle 001\rangle$. The method was detailed in Reference 21 and the CMSX-4 nominal composition is given in Table I. The ENGIN-X instrument at the ISIS Neutron and Muon Source, Rutherford Appleton Laboratory, Didcot, UK was used to carry out in-situ neutron diffraction. To conduct the cooling experiments, the sample was heated in an open optical furnace in air and a K-type thermocouple was used to measure temperature profiles. The experimental setup and details of detectors are found in References 22 through 24 . The measurement of lattice spacing was restricted to the longitudinal loading direction, i.e., specimen axis $\langle 001\rangle$. The samples was heated at $10{ }^{\circ} \mathrm{C}$ $\mathrm{min}^{-1}$ from room temperature up to $800^{\circ} \mathrm{C}$ and then at $5{ }^{\circ} \mathrm{C} \mathrm{min}$ min $^{-1}$ to the set temperature under zero load to allow for thermal expansion. Further details of the experimental setup are given in Reference 25 . A cooling experiment between $1000{ }^{\circ} \mathrm{C}$ and $950{ }^{\circ} \mathrm{C}$ using a nominal rate of $1{ }^{\circ} \mathrm{C} \mathrm{min}^{-1}$ was then performed starting with an initial stress of $350 \mathrm{MPa}$, which is the typical stress known to develop in the metal during solidification at $1000{ }^{\circ} \mathrm{C}$. ${ }^{[2]}$ The sample was held under strain control during cooling to replicate the strain development following solidification, analogous to the contraction of the metal that is constrained by the ceramic core. In isothermal tests, stress relaxation experiments under strain control were carried out at $950{ }^{\circ} \mathrm{C}$ and $1000{ }^{\circ} \mathrm{C}$ over a wide range of stresses. The initial stresses were 340 and $280 \mathrm{MPa}$, respectively, with an increment of $10 \mathrm{MPa}$. The experimental conditions were adopted from Reference 25 . The measured lattice strain corresponded to that of the composite (200) $\gamma+\gamma^{\prime}$ peak as a function of temperature and the stress is normalized by the 0.2 pct strain rate-dependent yield stress $\sigma_{0}$, i.e., $\sigma / \sigma_{0}$.

To separate the (200) $\gamma+\gamma^{\prime}$ peak from the neutron diffraction reflections measured, a fitting procedure and a refinement process, following Collins et al., ${ }^{[24]}$ were adopted to obtain the $d$-spacing of $\gamma$ and $\gamma^{\prime}$ phases - $d_{(200)}^{\prime}$ and $d_{(200)}^{\gamma^{\prime}}$. The lattice strains in the [100] direction, $\varepsilon_{(200)}^{\gamma}$, and $\varepsilon_{(200)}^{\gamma^{\prime}}$ were calculated using

$$
\left(\varepsilon_{(200)}^{\gamma, \gamma^{\prime}}\right)_{T}=\left(\frac{d_{(200)}^{\gamma, \gamma^{\prime}}-d_{(200)}^{\gamma, \gamma^{\prime}}(\sigma=0)}{d_{(200)}^{\gamma, \gamma^{\prime}}(\sigma=0)}\right)_{T},
$$

where $d_{(200)}^{\gamma, \gamma^{\prime}}(\sigma=0)$ is the relaxed value of $d$-spacing for the $\gamma$ or $\gamma^{\prime}$ phase when no stress is applied for a given temperature, $T$. Values of $d_{(200)}^{\gamma, \gamma^{\prime}}(\sigma=0)$ were obtained

Table I. The Compositions (in Weight Percent) of CMSX-4 Single-Crystal Superalloy

\begin{tabular}{cccccccccc}
\hline $\mathrm{Cr}$ & $\mathrm{Co}$ & $\mathrm{Mo}$ & $\mathrm{Re}$ & $\mathrm{W}$ & $\mathrm{Al}$ & $\mathrm{Ti}$ & $\mathrm{Ta}$ & $\mathrm{Hf}$ & $\mathrm{Ni}$ \\
\hline 6.5 & 9 & 0.6 & 3 & 6 & 5.6 & 1 & 6.5 & 0.1 & balance \\
\hline
\end{tabular}


from the fitted line profile positions for the data collected during heating. A polynomial function was fitted to $d_{(200)}^{j, \gamma^{\prime}}(\sigma=0)$ values as a function of temperature. This function was subsequently used to estimate $d_{(200)}^{p, \gamma^{\prime}}(\sigma=0)$ for the corresponding cooling temperature. The lattice misfit is calculated using $\delta=2\left(a_{(200)}^{\gamma^{\prime}}-a_{(200)}^{\gamma}\right) /\left(a_{(200)}^{\gamma^{\prime}}+a_{(200)}^{\gamma}\right)$, where $a_{(200)}^{\gamma}$ and $a_{(200)}^{\gamma^{\prime}}$ are the $\gamma$ and $\gamma^{\prime}$ lattice parameters, respectively.

Specimens for transmission electron microscopy (TEM) were prepared from the tested bar gauge section by electro-discharge machining 3-mm discs. Approximately 3 to 4 specimens were prepared from the gauge in each sample. Foils were produced from the disc specimens via electro-polishing using a solution of $10 \mathrm{vol}$ pct perchloric acid and 90 vol pet methanol. Given that each tensile bar was orientated with its axial direction within $5 \mathrm{deg}$ of the [001] direction, each TEM foil normal was close to the [001] direction. Foils were examined using a double-tilt specimen holder in a JEOL 2100 Plus TEM at an accelerating voltage of $200 \mathrm{kV}$.

\section{B. Analytical Model of Mechanical Deformation Upon Cooling}

The viscoplastic strain rate follows the Arrhenius-type relations, which can be defined as

$$
\dot{\varepsilon}^{\mathrm{vp}}=A_{0}^{\mathrm{vp}} \exp \left(-\frac{Q^{\mathrm{vp}}}{R T}\right)\left(\frac{\sigma}{\sigma_{0}}\right)^{n^{\mathrm{vp}}} .
$$

Here, $A_{0}^{\mathrm{vp}}, Q^{\mathrm{vp}}, n^{\mathrm{vp}}, R$, and $\sigma_{0}$ are the pre-exponent, activation energy, stress exponent, gas constant, and strain rate-dependent yield stress, respectively. In this work, the parameters in Eq. [2] were obtained from curve fitting of data from in-situ isothermal tests using neutron diffraction and the extensometer-measured strain, respectively, at temperatures $950{ }^{\circ} \mathrm{C}$ and $1000{ }^{\circ} \mathrm{C}$. For the cooling experiments, the cooling rate of $1{ }^{\circ} \mathrm{C} \min ^{-1}\left(0.017{ }^{\circ} \mathrm{C} \mathrm{s}^{-1}\right)$ was used with the initial stress, $\sigma_{\mathrm{i}}$, of $350 \mathrm{MPa}$, which is just above the yield stress at $1000{ }^{\circ} \mathrm{C}\left(325 \mathrm{MPa}\right.$ for typical strain rates of $10^{-4} \mathrm{~s}^{-1}$ to $10^{-5} \mathrm{~s}^{-1}$ ) and is applied to simulate the evolution of stress and time-dependent plastic strain during cooling between $1000{ }^{\circ} \mathrm{C}$ and $950{ }^{\circ} \mathrm{C}$. A three-dimensional (3D) model using ABAQUS/Standard was used with the available elastoplastic model with isotropic hardening,

$$
\sigma=\sigma_{\infty}+\left(\sigma_{y}-\sigma_{\infty}\right) \exp \left(-H \varepsilon^{p l}\right),
$$

where $\sigma_{\infty}$ is the ultimate yield stress, $\sigma_{y}$ is the yield stress, $\varepsilon^{p l}$ is plastic strain, and $H$ is the hardening coefficient $(\sim 0.5)$. The 3D model was compared with a simple one-dimensional (1D) model using the derived constitutive relations from Eq. [2], following Panwisawas et al. ${ }^{[25]}$ The numerical result is then compared with the experimental data.

\section{ETMT: In-Situ Cooling from $1300{ }^{\circ} \mathrm{C}$ to $1150{ }^{\circ} \mathrm{C}$ and Flow Stress}

The electro-thermal miniature test system (ETMT) developed at the National Physical Laboratory was used to measure the macroscopic stress and plastic strain; the latter was calculated by monitoring changes in resistance. ${ }^{[26,27]}$ Test-pieces of CMSX-4 single-crystal superalloy were electro-discharge machined (EDM) to have a nominal $2 \times 1 \mathrm{~mm}^{2}$ and $2 \times 2 \mathrm{~mm}^{2}$ cross section along the full length $(40 \mathrm{~mm})$ of the test-piece. The single-crystal test bars were directionally solidified and with axial orientations within $5 \mathrm{deg}$ from $\langle 001\rangle$. These samples were lightly ground with abrasive media thereafter to relieve surface stresses and the re-cast layer from resulting from EDM. The true plastic strain, $\varepsilon$, was measured, according to the change in resistance between the central 2 to $3 \mathrm{~mm}$ of the test-piece where the temperature profile is approximately uniform $\left( \pm 5^{\circ} \mathrm{C}\right)$ and given in Eq. [3]. ${ }^{[26]}$

Cooling experiments were carried out under conditions typical of directional solidification and a cooling rate of $0.1^{\circ} \mathrm{C} \mathrm{s}^{-1}$ was used throughout. Cooling was carried out in displacement control mode. In the absence of any sharp stress concentration feature in the rectangular ETMT test specimen cross section and in order to replicate casting conditions in turbine blades having stress concentration features, like fillet radii, the water-cooled grips were moved apart in order to plastically deform the central gauge length. The strain within the gauge volume is the sum of $\varepsilon^{\text {th }}$ and $\varepsilon^{\text {dis }}$, where $\varepsilon^{\text {th }}$ is the thermal strain and $\varepsilon^{\text {dis }}$ arises from the movement of the grips and are of the same algebraic sign. A range of grip displacement rates and sample cross sections were used and the plastic strain and stress induced during cooling from $1300{ }^{\circ} \mathrm{C}$ to $1150{ }^{\circ} \mathrm{C}$ was measured. In all cases prior to imposing a displacement rate during cooling, a standard heating/cooling cycle under zero load was applied between room temperature (RT) and the set temperature $\left(1300{ }^{\circ} \mathrm{C}\right)$. This enabled separation of the change in resistance arising during plastic deformation from that arising from a phase transformation (precipitation of $\gamma^{\prime}$ during cooling). This protocol is summarized in Table II.

Here S1, S2, and S3 are different samples undergoing continuous cooling under displacement control following the initial heating and cooling under zero load from RT to $1300{ }^{\circ} \mathrm{C}$ (I) and cooling under zero load on completion of loading (III).

Additionally, flow stress experiments were also carried out. A single sample was used so that the history dependence of prior accumulated deformation is taken into consideration on any subsequent deformation at the lower temperature. Only the temperature range between $1300{ }^{\circ} \mathrm{C}$ and $1200{ }^{\circ} \mathrm{C}$ was considered. The following methodology was adopted and is summarized in Table III. 
The plastic strain is given by

$$
\varepsilon=\ln \sqrt{\frac{R_{t}}{R_{s}}},
$$

where $R_{s}$ and $R_{t}$ are the resistance corresponding to zero load and during deformation, respectively.

\section{RESULTS}

\section{A. Cooling Deformation from $1000{ }^{\circ} \mathrm{C}$ to $900{ }^{\circ} \mathrm{C}$ : Neutron Diffraction and Microstructures}

During continuous cooling, the evolution of lattice parameter and temperature at $1{ }^{\circ} \mathrm{C} \mathrm{min}{ }^{-1}$ cooling rate is shown in Figure 1(a). After separation of the reflections corresponding with the $\gamma$ and $\gamma^{\prime}$ phases, $a_{(200)}^{\gamma^{\prime}}$ and $a_{(200)}^{\gamma}$ were obtained, see Figure 1(b). The evolution of the macroscopic stress commencing from an initial stress of $350 \mathrm{MPa}$ is shown in Figure 1(c). A decrease in stress of $105 \mathrm{MPa}$ within 15 minutes was observed at the initial stages of cooling in the temperature range, $984{ }^{\circ} \mathrm{C}<$ $T \leq 998{ }^{\circ} \mathrm{C}$. On further cooling between $950{ }^{\circ} \mathrm{C} \leq T \leq$ $984{ }^{\circ} \mathrm{C}$, the stress remains nearly constant. Figure $1(\mathrm{~d})$ shows the evolution of lattice strains within $\gamma$ and $\gamma^{\prime}$ phases, while the lattice misfit is shown in Figure 1(e). The strain drops quickly from when the temperature is in $984{ }^{\circ} \mathrm{C}<T \leq 998.5{ }^{\circ} \mathrm{C}$, where $\varepsilon_{(200)}^{\gamma^{\prime}}$ decreases from $5 \times 10^{-3}$ to $3.3 \times 10^{-3}$, resulting in the difference in lattice strain, $\Delta \varepsilon^{\mathrm{el}}$, of $-1.7 \times 10^{-3}$. The $\varepsilon_{(200)}^{\gamma}$ also decreases from $2.9 \times 10^{-3}$ to $1.8 \times 10^{-3}$, i.e., $\Delta \varepsilon^{\mathrm{el}}=$ $-1.1 \times 10^{-3}$. It can be seen that the lattice strains of both phases follow the variations in the macroscopic stress in Figure 1(a). Moreover, the misfit in the lattice parameter between $\gamma^{\prime}$ and $\gamma$ is negative, i.e., $a_{(200)}^{\gamma^{\prime}}<a_{(200)}^{\gamma}$ but with a small magnitude. The observed misfit is comparable to the values reported by Reference 28 . A near-constant stress during subsequent cooling down to $950{ }^{\circ} \mathrm{C}$ indicates that thermal strain must be almost primarily accommodated through plastic deformation. This is because $\Delta \sigma \approx 0$ and under strain control, $\Delta \varepsilon=0$, there is a perfect balance between hardening and recovery. It is worth noting that in the cooling cycle, $950{ }^{\circ} \mathrm{C}<T \leq 994{ }^{\circ} \mathrm{C}$, the $\varepsilon_{(200)}^{\gamma}$ fluctuates by $\pm 0.5 \times$ $10^{-3}$, while $\varepsilon_{(200)}^{\gamma^{\prime}}$ shows a marginal increase of about $0.2 \times 10^{-3}$.

Figure 2 shows various regions of interest in the microstructure following relaxation. The bright-field images were obtained under near [001] conditions using either $\boldsymbol{g}=200 / 220$. The sample exhibited a high-density interfacial dislocation network at the $\gamma / \gamma^{\prime}$ interface (Figure 2(a)). The interfacial dislocations were present either as rows or in cross-cross configuration wrapped around the surface of the $\gamma^{\prime}$ precipitates. Some areas as the one shown in Figure 2(b) also showed a low dislocation density in the horizontal and vertical $\gamma$ channels, implying an inhomogeneous defect distribution. The sample also showed the presence of long segments of stacking faults (typically $>5 \mu \mathrm{m}$ ) in the $\gamma$ phase cutting across the coherent precipitates, (Figure 2(c)). The $\gamma^{\prime}$ precipitates primarily showed a defect-free structure with a very small fraction of dislocations shearing them. Within the precipitates, the dislocations were present as both pairs and dipoles. Using two-beam conditions, the dislocations, as denoted from $A$ to $G$ in Figure 2(d), were identified to be partials with Burgers vector of $\frac{a}{2}\langle 10 \overline{1}\rangle$. Such dislocations generally bound an anti-phase boundary within a $\gamma^{\prime}$ precipitate on $\{111\}$. Since during cooling from $1000^{\circ} \mathrm{C}$ stress relaxation takes place in the sample following the applied stress of $350 \mathrm{MPa}$ (which is greater than the yield stress of CMSX-4, i.e., $325 \mathrm{MPa}$ ), the lower dislocation density observed clearly indicates the occurrence of recovery processes. There is a decrease in elastic strain (and therefore stress), which has been converted to time-dependent plastic strain.

Figure 3 shows the evolution of strain rate with $\sigma / \sigma_{0}$ at $950{ }^{\circ} \mathrm{C}$ and $1000{ }^{\circ} \mathrm{C}$. It can be observed that at each temperature and for any given time, the extent of stress relaxation increases with $\sigma / \sigma_{0}$. At $1000{ }^{\circ} \mathrm{C}$ and $950{ }^{\circ} \mathrm{C}$, a power law fit is applied to obtain a best fit for the strain rate under conditions of strain control. Equation [2] can therefore become

$$
\dot{\varepsilon}^{\text {rel }}=\mathrm{A}^{\mathrm{rel}} \exp \left(\frac{\sigma}{\sigma_{0}}\right)^{\mathrm{n}^{\mathrm{rel}}},
$$

where the activation energy is included within the pre-exponential factor. The corresponding fitting parameters are given in Reference 25 with the activation energy assumed to be a constant for all temperatures considered in this study. A comparable stress exponent $\left(\mathrm{n}^{\mathrm{rel}} \approx 10\right.$ to 12$)$ is obtained at both temperatures.

Figure 4 illustrates the evolution of calculated stresses after cooling from $1000{ }^{\circ} \mathrm{C}$ to $950{ }^{\circ} \mathrm{C}$, compared with the macroscopic stress measurements obtained from the neutron diffraction experiment. The variation of von Mises stress at the central node of the specimen gauge length with temperature using the elastoplastic model indicates that the stress increases continuously when the temperature decreases from $1000{ }^{\circ} \mathrm{C}$ irrespective of the initial stress. The von Mises stress for an initial stress of $350 \mathrm{MPa}$ tests increases by $\sim 70 \mathrm{MPa}$ when cooling between $1000{ }^{\circ} \mathrm{C}$ and $950{ }^{\circ} \mathrm{C}$. As shown in Figure 4, the stresses calculated using the elastoplastic model is consistently higher than those measured experimentally and does not match the trend. This difference is attributed to softening that occurs during cooling even at the casting time-scale. This effect can be captured with viscoplasticity, which is absent in the elastoplastic model. Therefore, using the derived viscoplastic constitutive law implemented in a simple viscoplastic model, the stresses can be re-calculated. The calculated stress during cooling shows some relaxation but the prediction still over-estimates the experimentally measured stress.

It must be inferred therefore that the discrepancy between measurement and the viscoplastic model arises from the lack of consideration of the history dependence of microstructure in deriving the viscoplastic law. This is because the accumulated deformation at a higher 
Table II. Experimental Procedure Adopted During the Cooling Experiments Using ETMT

(I) Zero Load (Heat and

Cool)

(II) Loading Experiment

(III) Zero Load (Cool)

1. Heat at $5^{\circ} \mathrm{C} \mathrm{s}^{-1}$ from 1 . heat at $1^{\circ} \mathrm{C} \mathrm{s}^{-1}$ from $1150^{\circ} \mathrm{C}$ to $1300^{\circ} \mathrm{C}$ (zero load)

RT to $1150^{\circ} \mathrm{C}$

2. cool from $1300{ }^{\circ} \mathrm{C}$ to $1150{ }^{\circ} \mathrm{C}$ at $0.1{ }^{\circ} \mathrm{C} \mathrm{s}^{-1}$ under displacement

2. Heat at $1{ }^{\circ} \mathrm{C} \mathrm{s}^{-1}$ from control, using grip displacement rates of $0.04 \mu \mathrm{m} / \mathrm{s}(\mathbf{S 1}), 0.10 \mu \mathrm{m} / \mathrm{s}$

$1150{ }^{\circ} \mathrm{C}$ to $1300{ }^{\circ} \mathrm{C}$

(S2), and $0.4 \mu \mathrm{m} / \mathrm{s}$ (S3)

1. cool at $1{ }^{\circ} \mathrm{C} \mathrm{s}^{-1}$ from

$1300{ }^{\circ} \mathrm{C}$ to $1150{ }^{\circ} \mathrm{C}$ (zero

load)

2. cool at $5{ }^{\circ} \mathrm{C} \mathrm{s}^{-1}$ from

$1150{ }^{\circ} \mathrm{C}$ to RT (zero load)

$1300{ }^{\circ} \mathrm{C}$ to $1150{ }^{\circ} \mathrm{C}$

Table III. Experimental Procedure Adopted During the Flow Stress Experiments at Temperatures of $1200{ }^{\circ} \mathrm{C}$ to $1300{ }^{\circ} \mathrm{C}$

(I) Zero Load (Heat and

Cool)

(II) Zero Load (Heat)

(III) Zero Load (Cool)

1. Heat at $5^{\circ} \mathrm{C} \mathrm{s}^{-1}$ from 1 . heat at $1{ }^{\circ} \mathrm{C} \mathrm{s}^{-1}$ from $1150{ }^{\circ} \mathrm{C}$ to $1300{ }^{\circ} \mathrm{C}$ (zero load)

RT to $1150{ }^{\circ} \mathrm{C} \quad 2$. cool for 4 conditions:

2. Heat at $1{ }^{\circ} \mathrm{C} \mathrm{s}^{-1}$ from $2.1 \mathrm{cool}$ at $1{ }^{\circ} \mathrm{C} \mathrm{s}^{-1}$ from $1300^{\circ} \mathrm{C}$ to $1280{ }^{\circ} \mathrm{C}$ (zero load). Deformed in

$1150{ }^{\circ} \mathrm{C}$ to $1300{ }^{\circ} \mathrm{C}$

3. Cool at $1{ }^{\circ} \mathrm{C} \mathrm{s}^{-1}$ from $2.2 \mathrm{cool}$ at $0.1^{\circ} \mathrm{C} \mathrm{s}^{-1}$ from $1280^{\circ} \mathrm{C}$ to $1260{ }^{\circ} \mathrm{C}$ (zero load). Deformed

$1300{ }^{\circ} \mathrm{C}$ to $1150{ }^{\circ} \mathrm{C} \quad$ in tension at $0.04 \mu \mathrm{m} / \mathrm{s}$ at $1260{ }^{\circ} \mathrm{C}$. Unload at 1.1 pet plastic strain

$2.3 \mathrm{cool}$ at $0.1{ }^{\circ} \mathrm{C} \mathrm{s}^{-1}$ from $1260^{\circ} \mathrm{C}$ to $1240{ }^{\circ} \mathrm{C}$ (zero load). Deformed in tension at $0.04 \mu \mathrm{m} / \mathrm{s}$ at $1240{ }^{\circ} \mathrm{C}$. Unload at 1.7 pct plastic strain

2.4 cool at $0.1{ }^{\circ} \mathrm{C} \mathrm{s}^{-1}$ from $1240{ }^{\circ} \mathrm{C}$ to $1220^{\circ} \mathrm{C}$ (zero load). Deformed in tension at $0.04 \mu \mathrm{m} / \mathrm{s}$ at $1220^{\circ} \mathrm{C}$. Unload at 2.5 pct plastic strain

temperature will play a role on the subsequent deformation at the lower temperature during continuous cooling. This will become prominent at temperatures approaching the solvus as well as at lower strain rates, when viscoplasticity will be dominant. In the isothermal loading experiments, where individual samples are considered at a given temperature and stress condition, this history dependence will not be captured.

\section{B. Cooling Deformation from $1300^{\circ} \mathrm{C}$ to $1150^{\circ} \mathrm{C}$ and Flow Stress Measurements: ETMT}

The history dependence and the role of accumulated deformation during cooling were investigated between $1300{ }^{\circ} \mathrm{C}$ and $1150{ }^{\circ} \mathrm{C}$.

Figures 5(a) through (c) show the evolution of plastic strain, strain rate, and macroscopic stress, respectively, under different conditions of loading, i.e., displacement rates. It can be observed that the developing plastic strain increases with cooling and is strongly dependent on the strain rate. The plastic strain over the temperature range is $\times$ [1.5 to 2] greater for a grip displacement rate of $0.1 \mu \mathrm{m} / \mathrm{s}$ (S2), compared with cooling under a grip displacement rate of $0.04 \mu \mathrm{m} / \mathrm{s}$ (S1). The evolution of stress is similar in both cases, where in the case of the higher displacement rate the stress being only as much as $5 \mathrm{MPa}$ larger than for the lower displacement rate at $1150{ }^{\circ} \mathrm{C}$. However, for larger displacement rates $(0.4$ $\mu \mathrm{m} / \mathrm{s}$ ) some key differences are observed compared to the lower displacement rates. For a displacement rate of $0.4 \mu \mathrm{m} / \mathrm{s}$ (S3), the evolution of plastic strain closely follows that at $0.04 \mu \mathrm{m} / \mathrm{s}$ up to $1230{ }^{\circ} \mathrm{C}$ but is lower thereafter. There is nevertheless a marked increase in stress. Further in all the stress plots, a rapid increase in stress is observed after an initial gradual increase below a threshold temperature. This threshold temperature is $1230{ }^{\circ} \mathrm{C}$ for displacement rates up to $0.1 \mu \mathrm{m} / \mathrm{s}$, but increases to $1240{ }^{\circ} \mathrm{C}$ for $0.4 \mu \mathrm{m} / \mathrm{s}$. The average strain rate corresponding to $0.04 \mu \mathrm{m} / \mathrm{s}(\mathrm{S} 1), 0.1 \mu \mathrm{m} / \mathrm{s}$ (S2), and $0.4 \mu \mathrm{m} / \mathrm{s}$ (S3) displacement rates are $1.5 \times 10^{-5} \mathrm{~s}^{-1}, 3 \times$ $10^{-5} \mathrm{~s}^{-1}$, and $2 \times 10^{-4} \mathrm{~s}^{-1}$, respectively. Given the marked increase in stress below the threshold temperature with the onset of work hardening, it is appropriate to consider the temperature range between $1300{ }^{\circ} \mathrm{C}$ and $1150{ }^{\circ} \mathrm{C}$ as two distinct regions, the boundary of which corresponds to the threshold temperature. Accordingly we split the temperature range into two sub-regions: $1300{ }^{\circ} \mathrm{C}$ to $1220{ }^{\circ} \mathrm{C}$ and $1220{ }^{\circ} \mathrm{C}$ to $1150{ }^{\circ} \mathrm{C}$. In this preliminary study, the focus is on the temperature range of $1300{ }^{\circ} \mathrm{C}$ to $1220{ }^{\circ} \mathrm{C}$, where the emphasis is to investigate the history dependence from prior accumulated deformation.

Accordingly Figure 6 presents the variation of flow stress with plastic strain over a range of temperatures using the approach outlined in Section II-C. In this case, a single sample is used in order to investigate the evolution of stress with plastic strain at a given temperature when the prior accumulated deformation at the higher temperature is present. The strain rates in the cooling and flow stress experiments are comparable: [1-4] $\times 10^{-5} \mathrm{~s}^{-1}$ for the lower displacement rates. A saturation stress is attained beyond 0.05 pct plastic strain: $6.5 \mathrm{MPa}$ at $1280{ }^{\circ} \mathrm{C}, 7.5 \mathrm{MPa}$ at $1260{ }^{\circ} \mathrm{C}$, $9.5 \mathrm{MPa}$ at $1240{ }^{\circ} \mathrm{C}$, and $22.5 \mathrm{MPa}$ at $1220{ }^{\circ} \mathrm{C}$. With decreasing temperature there is a marked increase in the saturation stress, specifically between $1240{ }^{\circ} \mathrm{C}$ and 


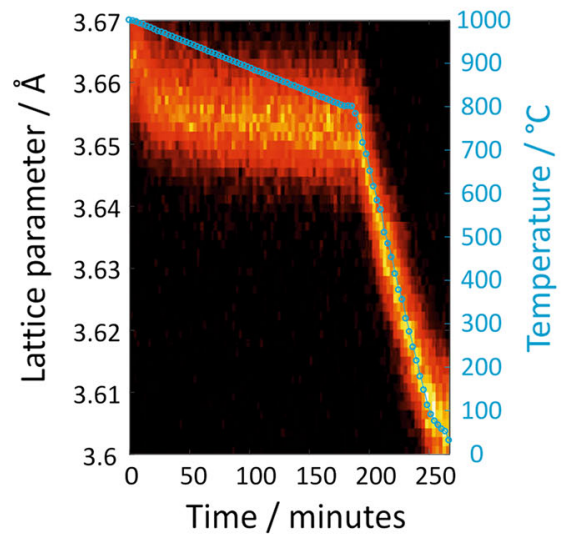

(a)

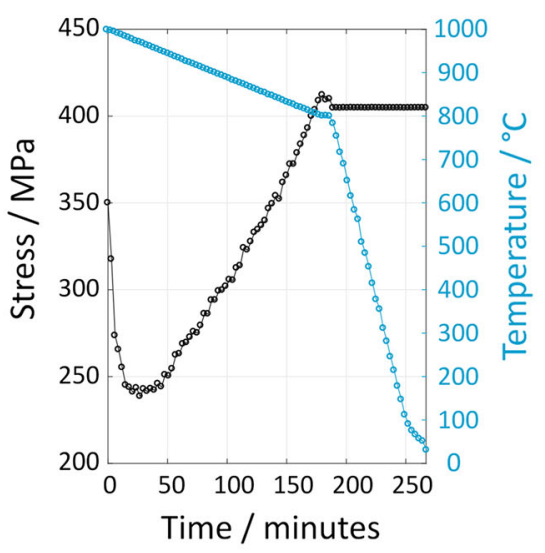

(c)
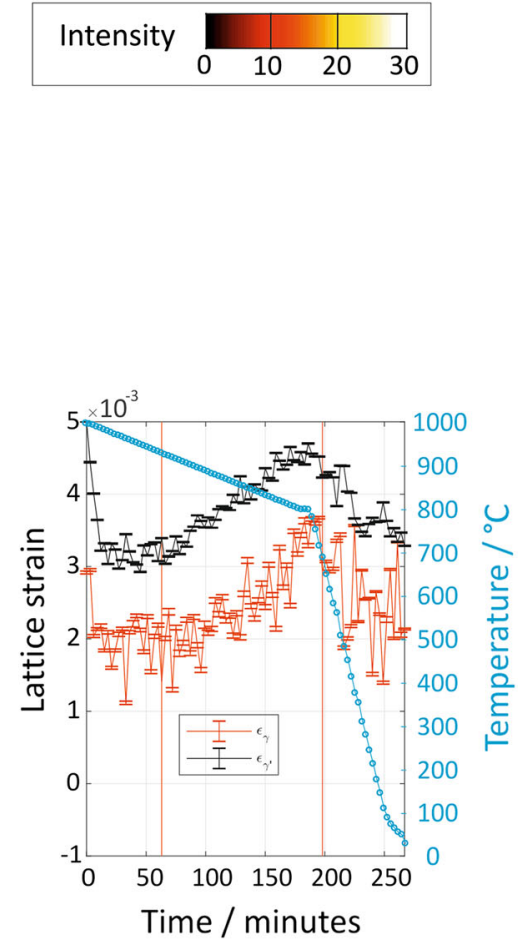

(d)

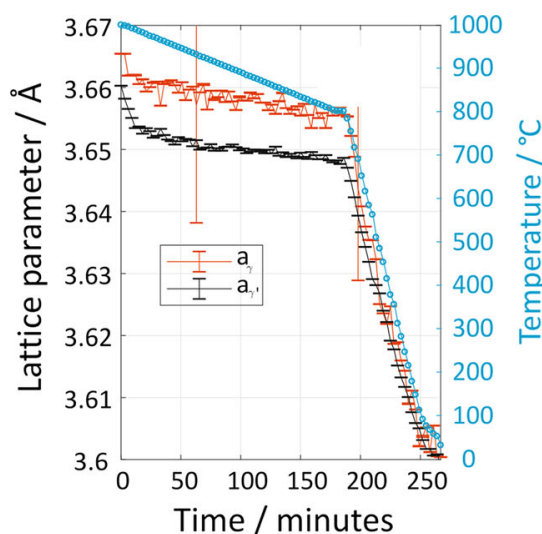

(b)

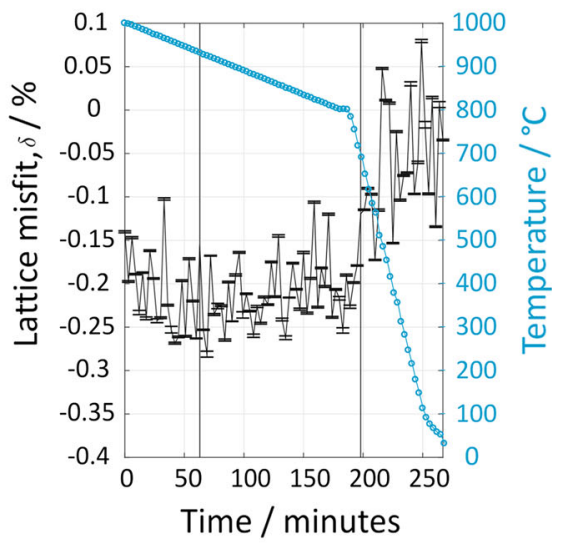

(e)

Fig. 1-(a) Lattice parameter evolution during cooling; (b) the separation of the $\gamma$ and $\gamma^{\prime}$ lattice parameters corresponding to raw data shown in (a); (c) experimentally measured stress during continuous cooling from the initial stress of $350 \mathrm{MPa}$; $(d)$ lattice strains in $\gamma$ and $\gamma^{\prime}$ during continuous cooling following an initial stress at $350 \mathrm{MPa}$. The variation of lattice misfit with time is shown in $(e)$.

$1220^{\circ} \mathrm{C}$ as work hardening increasingly begins to prevail, as can also be observed in Figure 5(c). The accumulated plastic strain and saturation stress corresponding to the flow stress measurements at successive test temperatures are listed in Tables IV and V, respectively. For comparison, the plastic strain and stress in the cooling experiments is also included.

From Table IV, it can be observed that the evolution of plastic strain in the flow stress experiment is comparable to that in the cooling experiments for the lower displacement rates, with a particularly good agreement seen for the $0.1 \mu \mathrm{m} / \mathrm{s}$ displacement rate. From Table V, it can be seen that the saturation stress in the flows stress measurements shows good correlation with 0.04 and 0.1 $\mu \mathrm{m} / \mathrm{s}$ displacement rates, with a particularly good agreement with $0.1 \mu \mathrm{m} / \mathrm{s}$ displacement rate again. However, for the higher displacement rate of $0.4 \mu \mathrm{m} / \mathrm{s}$, the saturation stress is under-estimated below $1240{ }^{\circ} \mathrm{C}$.

\section{DISCUSSION}

The methodology adopted in the flow stress measurements in using a single sample over the entire temperature range is intended to take into account the accumulated deformation induced at higher temperatures during cooling. Not only does this identify the pedigree of sample required for any isothermal creep tests in deriving a viscoplastic law for modeling the evolution of stress in the cooling experiments, such as Eq. [5], but also the appropriate stresses in the vicinity of the saturation stress. The reasonably good correlation of the evolution of plastic strain and stress (Figures 5(a) through (c) and Tables IV and V) in the cooling experiments with that of the flow stress experiments at the lower strain rates up to $1220{ }^{\circ} \mathrm{C}$ clearly justifies such an approach. In the as-cast microstructure, significant micro-segregation exists resulting in a range in solvus temperature. Using the Scheil model and the thermodynamic software JMatPro ${ }^{\mathrm{TM}},{ }^{[29]}$ the solvus temperature at the dendrite core is $1205^{\circ} \mathrm{C}$, while at the dendrite periphery before the onset of the eutectic reaction is $1305^{\circ} \mathrm{C}$. When back-diffusion is considered, freezing of the inter-dendritic region commences at $1320^{\circ} \mathrm{C}$ with nucleation of $\gamma^{\prime}{ }^{[30]}$ From the Scheil model, the total $\gamma^{\prime}$ content is 24 pet at $1220^{\circ} \mathrm{C}$ and 38 pet at $1150{ }^{\circ} \mathrm{C}$, which includes the dendrite cross section and adjacent inter-dendritic region. It is clear therefore that up to the threshold temperature even though some $\gamma^{\prime}$ does exist, there is hardly any work hardening and the evolution of 

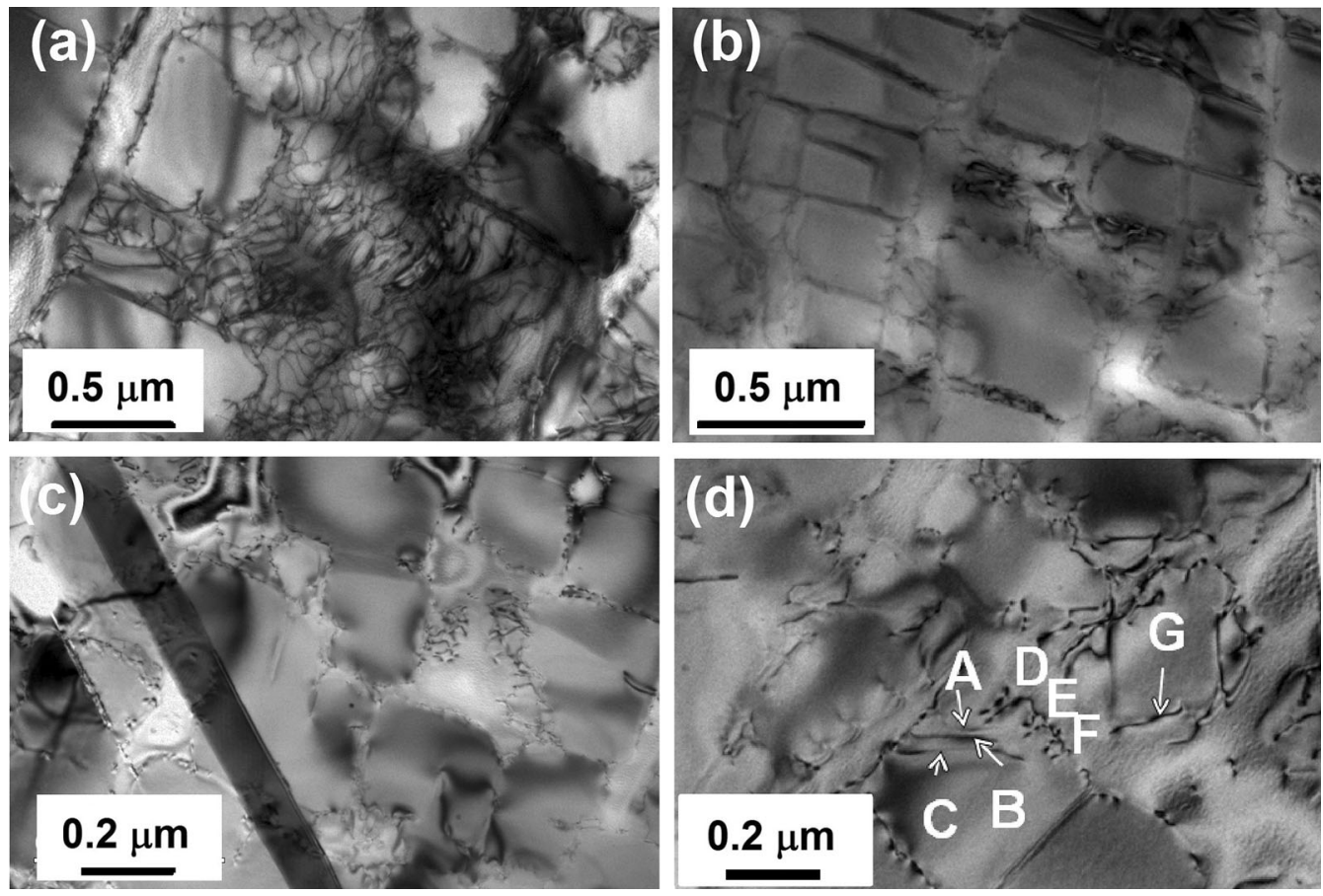

Fig. 2-Bright-field TEM micrographs showing the deformation microstructure in a specimen cooled from $1000{ }^{\circ} \mathrm{C}$ with an initial applied stress of $350 \mathrm{MPa}$. Regions showing $(a)$ a high density of interfacial dislocation networks alongside $(b)$ low defect densities and $(c)$ stacking faults in the specimen foil. (d) The dislocations A to $\mathrm{G}$ that sheared the $\gamma^{\prime}$ precipitates were determined to be $\frac{a}{2}\langle 1 \overline{1} 0\rangle$ type.

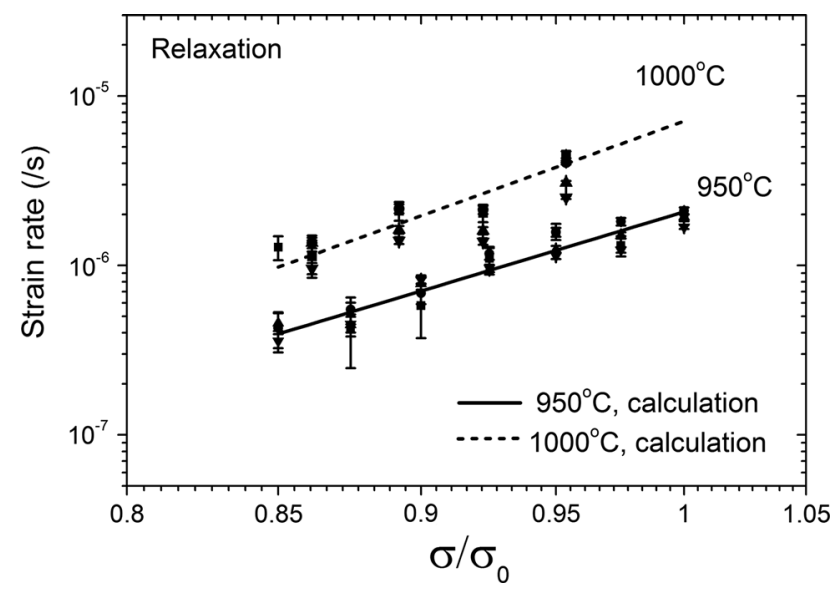

Fig. 3-Time-dependent strain rates during isothermal loading strain control (fixed grips and zero displacement) at $950{ }^{\circ} \mathrm{C}$ and $1000{ }^{\circ} \mathrm{C}$, reproduced with permission from Ref. [25].

plastic strain is dominated by viscoplastic deformation. But beyond a critical fraction of precipitates, work hardening occurs and results in a marked increase in stress. The deformation up to $1220^{\circ} \mathrm{C}$ is primarily viscoplastic in nature for strain rates up to $5 \times 10^{-5} \mathrm{~s}^{-1}$, but for higher strain rates, $10^{-4} \mathrm{~s}^{-1}$ it is clear that work hardening occurs and the stresses in the cooling experiment significantly exceed the saturation stresses in the flow stress experiments. It is not surprising therefore that the evolution of stress with temperature in the case of stress relaxation (Figure 4) is markedly over-estimated, since the history dependence or prior accumulated deformation at the successive higher temperature is

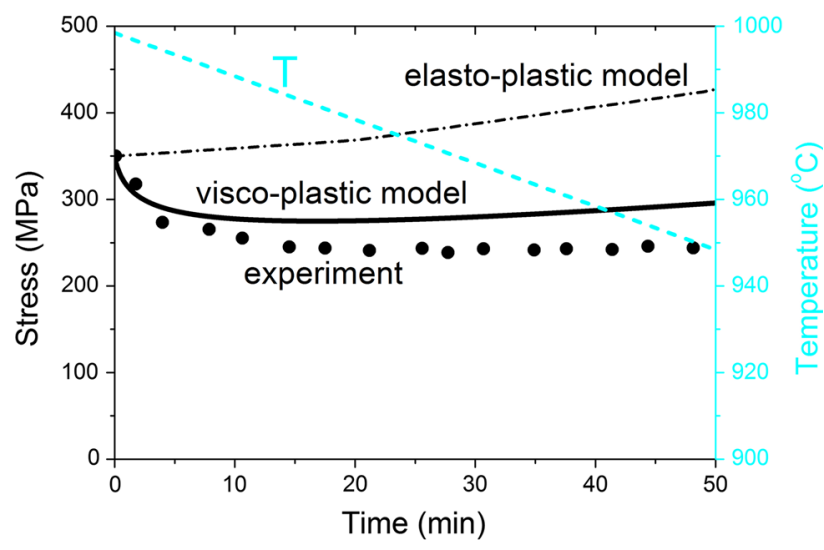

Fig. 4-The evolution of stress from calculations and juxtaposed experimentally measured stress at $350 \mathrm{MPa}$ applied stress. These are compared with evolution of stress from a viscoplastic and elastoplastic model calculation alongside experimentally measured macroscopic stress.

not considered in the derivation of Eq. [4]. By choosing the approach as in the flow stress measurements, an appropriate viscoplastic law can be derived, which would give a more accurate prediction of the stress. This is the subject of an ongoing study and to be presented elsewhere.

It is also worth making some comments on the evolution of stress in lieu of possible deformation mechanisms. There are limited investigations of the response of the microstructure at such small mass fraction of precipitates. For deformation well below the solvus temperature, $\sim 750{ }^{\circ} \mathrm{C}$ or lower, stacking 


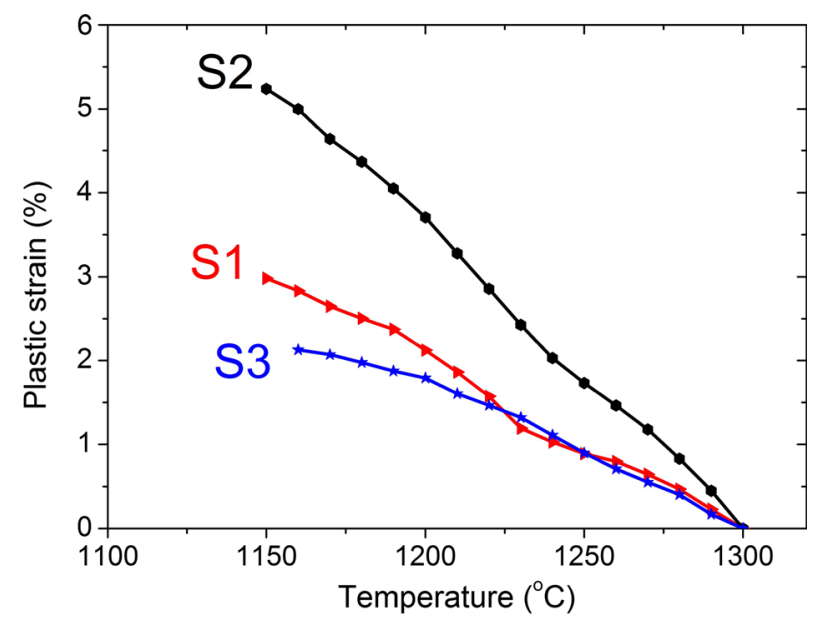

(a)

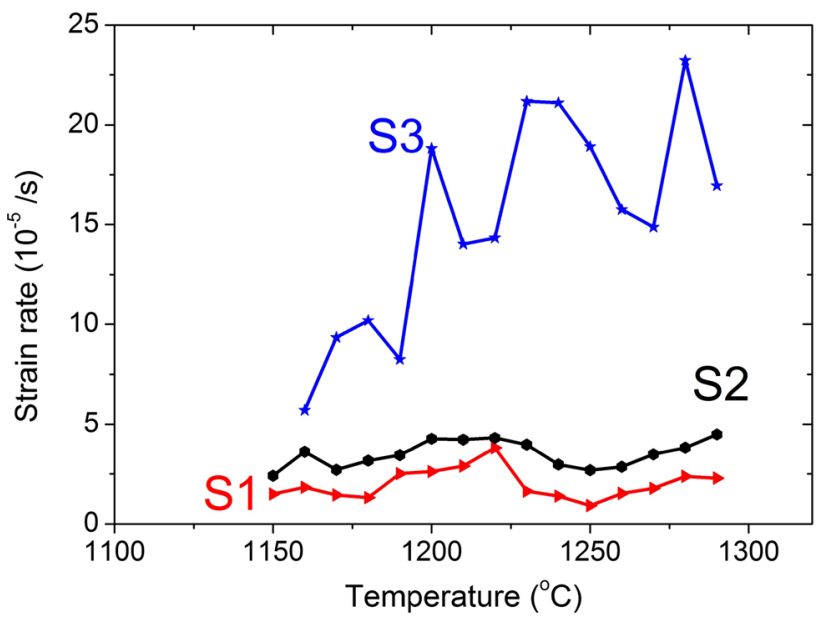

(b)

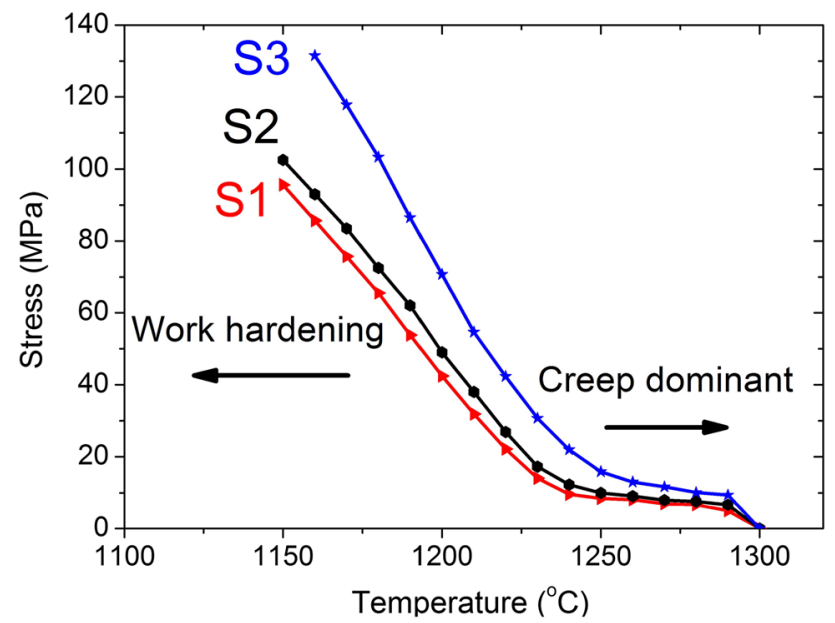

(c)

Fig. 5-Experimentally (a) plastic strain, (b) strain rate, and (c) macroscopic stress evolution during in-situ cooling at $0.1^{\circ} \mathrm{C} / \mathrm{s}$ from $1300{ }^{\circ} \mathrm{C}$ with different imposed grip displacement rates.

faults were reported within $\gamma^{\prime}$ precipitates $^{[1,16]}$ and in case of inter-dendritic $\gamma / \gamma^{\prime}$ phases it was observed that dislocation pairs cut through $\gamma^{\prime}$ and a high density of dislocations was observed at the interface between the inter-dendritic $\gamma / \gamma^{\prime}$ eutectic phases and the matrix. ${ }^{[20]}$

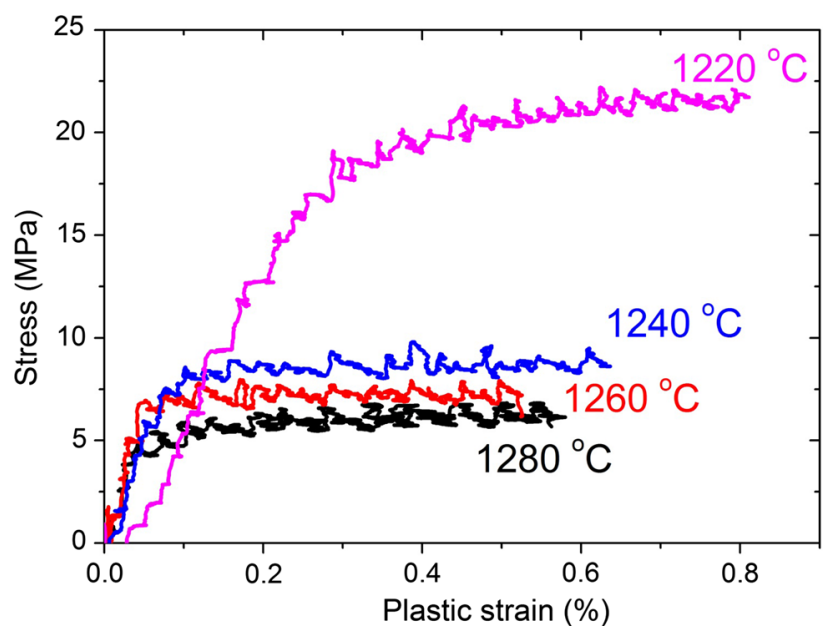

Fig. 6-Flow curves showing evolution of plastic strain with stress over a range of temperatures between $1300{ }^{\circ} \mathrm{C}$ and $1220{ }^{\circ} \mathrm{C}$ using a single sample.

However, at temperatures above $1050{ }^{\circ} \mathrm{C}$ and up to $1200{ }^{\circ} \mathrm{C}$, the dislocations were concentrated at the $\gamma / \gamma^{\prime}$ interface and wrapped around the precipitates. ${ }^{[1]}$ Therefore, between $1300{ }^{\circ} \mathrm{C}$ and $1220{ }^{\circ} \mathrm{C}$, the viscoplastic strain must arise from glide of dislocations within $\gamma$ channels resulting in enhanced ductility: $\sigma \sim$ [22-26] $\mathrm{MPa}$ at $1220{ }^{\circ} \mathrm{C}$ for strain rate $\sim 10^{-5} \mathrm{~s}^{-1}$, in the cooling experiments (S1 and $\mathrm{S} 2$ ). It can be argued that the dislocations concentrated at the $\gamma / \gamma^{\prime}$ interface would arise following the precipitation of the precipitates, while any further straining below $1220{ }^{\circ} \mathrm{C}$ will be accompanied by increasing extent of shearing of precipitates and stacking faults leading to work hardening and increasing stress. This aspect is further corroborated when examining the microstructure that evolves following prominent stress relaxation at temperatures well below the solvus, as shown in Figure 2. In this case, the viscoplastic strain that accompanies relaxation is derived partly through the movement of dislocation pairs and dipoles that shear $\gamma^{\prime}$ but primarily through the marked presence of long segments/ribbons of extended stacking faults within $\gamma$ phase traversing several precipitates, as also reported in other studies. ${ }^{\text {[3] }}$

\section{CONCLUSIONS}

1. Viscoplasticity during in-situ cooling using both neutron diffraction and ETMT is dependent on the applied stress and constraints imposed. At the lower temperatures around $1000{ }^{\circ} \mathrm{C}$, relaxation is accompanied by a prominent decrease in stress, while at high temperatures close to the solvus, $1300{ }^{\circ} \mathrm{C}$ to $1220{ }^{\circ} \mathrm{C}$, viscoplastic strain is accompanied only by a small increase in stress for low strain rates.

2. The material softens as indicated by a low dislocation density in the constituent phases when stress relaxation is dominant with only limited shearing of the $\gamma^{\prime}$ precipitates. Lattice strain reduction observed in $\gamma$ and $\gamma^{\prime}$ phases during relaxation is also accommodated through the formation of interfacial 
Table IV. Plastic Strain and Stress in the Temperature Range $1300{ }^{\circ} \mathrm{C}$ to $1220{ }^{\circ} \mathrm{C}$, Where the Underlined Number Refers to Plastic Strain Induced at That Temperature. Also Included Is the Plastic Strain in the Cooling Experiments

\begin{tabular}{lllll}
\hline & \multicolumn{3}{c}{ Plastic Strain (Percent) } \\
\cline { 2 - 5 } Test Conditions & $1280{ }^{\circ} \mathrm{C}$ & \multicolumn{1}{c}{$1260{ }^{\circ} \mathrm{C}$} & $1240{ }^{\circ} \mathrm{C}$ & $1.08+\underline{0.62}=1.70$ \\
\hline Flow Stress Experiment & 0.56 & $0.56+\underline{0.52}=1.08$ & 1.03 & $1.70+\underline{0.79}=2.49$ \\
Cooling at $0.04 \mu \mathrm{m} / \mathrm{s}$ & 0.47 & 0.80 & 2.03 & 1.57 \\
Cooling at $0.1 \mu \mathrm{m} / \mathrm{s}$ & 0.83 & 1.46 & 1.11 & 2.86 \\
Cooling at $0.4 \mu \mathrm{m} / \mathrm{s}$ & 0.4 & 0.7 & 1.46 \\
\hline
\end{tabular}

Table V. Saturation Stress in the Flow Stress Measurements at Different Temperatures and also Included Is the Corresponding Stress in the Cooling Experiments at Those Temperatures

\begin{tabular}{lcrrr}
\hline & \multicolumn{3}{c}{ Stress (MPa) } \\
\cline { 2 - 5 } Test Conditions & $1280{ }^{\circ} \mathrm{C}$ & $1260{ }^{\circ} \mathrm{C}$ & $1240{ }^{\circ} \mathrm{C}$ & 9.5 \\
\hline Flow Stress Experiment & 6.5 & 7.5 & 9.6 & 22.5 \\
Cooling at $0.04 \mu \mathrm{m} / \mathrm{s}$ & 6.7 & 8.1 & 12.3 & 22.2 \\
Cooling at $0.1 \mu \mathrm{m} / \mathrm{s}$ & 7.6 & 9.1 & 26.9 \\
Cooling at $0.4 \mu \mathrm{m} / \mathrm{s}$ & 10.1 & 13.0 & 22.0 & 42.3 \\
\hline
\end{tabular}

dislocation networks and migration of stacking faults in the $\gamma$ phase.

3. A viscoplastic law derived from isothermal creep and stress relaxation experiments indicates that when stress relaxation is dominant, the history dependence of prior induced deformation during cooling must be taken into account.

4. Viscoplastic behavior during in-situ cooling of samples measured using an ETMT shows that at high-temperature deformation in the $1220^{\circ} \mathrm{C}$ to $1300{ }^{\circ} \mathrm{C}$ range creep dominates, but below a threshold temperature, typically $1220{ }^{\circ} \mathrm{C}$ work hardening begins to prevail with increasing $\gamma^{\prime}$ mass fraction. This results in a rapid increase in stress for strain rates typically $10^{-5} \mathrm{~s}^{-1}$, which is typically encountered in casting conditions.

5. Flow stress experiments designed to incorporate the history dependence of prior accumulated deformation accurately confirm the evolution of stress in the cooling experiments. The saturation stresses in the flow stress experiments show very good agreement with the stresses measured in the cooling experiments when viscoplastic deformation is dominant.

\section{ACKNOWLEDGMENTS}

The authors acknowledge the help of Mr. Bela Kantor from the Precision Foundry Bristol, RollsRoyce plc who helped in initial TEM sample preparation. One of the authors N.D. acknowledges RollsRoyce plc who funded this work. A.B. acknowledges the support of Dr. Finn Giuliani with the access to the TEM at Harvey Flower Electron Microscopy Suite,
Imperial College London. Dr. Joe Kelleher and Dr. Saurabh Kabra of Science and Technology Facilities Council are gratefully acknowledged for their help on neutron diffraction measurement at ISIS Neutron and Muon Source, Rutherford Appleton Laboratory, Didcot, UK.

\section{OPEN ACCESS}

This article is distributed under the terms of the Creative Commons Attribution 4.0 International License (http://creativecommons.org/licenses/by/4.0/), which permits unrestricted use, distribution, and reproduction in any medium, provided you give appropriate credit to the original author(s) and the source, provide a link to the Creative Commons license, and indicate if changes were made.

\section{REFERENCES}

1. C. Panwisawas, H.N. Mathur, J.-C. Gebelin, D.C. Putman, C.M.F. Rae, and R.C. Reed: Acta Mater., 2013, vol. 61, pp. 51-66.

2. C. Panwisawas, J.-C. Gebelin, and R.C. Reed: Mater. Sci. Technol., 2013, vol. 29, pp. 843-53.

3. M. Dupeux, J. Henriet, and M. Ignat: Acta Metall., 1987, vol. 35, pp. 2203-12.

4. H. Wang, B. Clausen, C.N. Tome, and P.D. Wu: Acta Mater., 2013, vol. 61, pp. 1179-88.

5. R.C. Reed: The Superalloys: Fundamentals and Applications, Cambridge University Press, Cambridge, 2006.

6. J. Svoboda and P. Lukáš: Acta Mater., 1997, vol. 45, pp. 125-35.

7. J. Preußner, Y. Rudnik, H. Brehm, R. Völkl, and U. Glatzel: Int. J. Plast., 2009, vol. 25, pp. 973-94.

8. J. Cormier and G. Cailletaud: Mater. Sci. Eng. A, 2010, vol. 527, pp. $6300-12$

9. J. Cormier, M. Jouiad, F. Hamon, P. Villechaise, and X. Milhet: Philos. Mag. Lett., 2010, vol. 90, pp. 611-20. 
10. J. Cormier, X. Milhet, and J. Mendez: Acta Mater., 2007, vol. 55, pp. $6250-59$.

11. R. Giraud, Z. Hervier, J. Cormier, G. Saint-Martin, F. Hamon, X. Milhet, and J. Mendez: Metall. Mater. Trans. A, 2013, vol. 44A, pp. 131-46.

12. J.-B. le Graverend, J. Cormier, F. Gallerneau, P. Villechaise, S. Kruch, and J. Mendez: Int. J. Plast., 2014, vol. 59, pp. 55-83.

13. J.-B. le Graverend, J. Cormier, F. Gallerneau, S. Kruch, and J. Mendez: Mater. Des., 2014, vol. 56, pp. 990-97.

14. A. Ma, D. Dye, and R.C. Reed: Acta Mater., 2008, vol. 56, pp. $1657-70$.

15. Z. Zhu, H.C. Basoalto, N. Warnken, and R.C. Reed: Acta Mater., 2012, vol. 60, pp. 4888-4900.

16. D.C. Cox, B. Roebuck, C.M.F. Rae, and R.C. Reed: Mater. Sci. Tech., 2003, vol. 19, pp. 440-46.

17. N. D’Souza, J. Kelleher, C.L. Qiu, S.-Y. Zhang, S. Gardner, R.E. Jones, D.C. Putman, and C. Panwisawas: Acta Mater., 2016, vol. 106, pp. 322-32.

18. C.L. Qiu, N. D'Souza, J. Kelleher, and C. Panwisawas: Mater. Des., 2017, vol. 114, pp. 475-83.

19. N. D'Souza, J. Kelleher, S. Kabra, and C. Panwisawas: Mater. Sci. Eng. A, 2017, vol. 681, pp. 32-40.
20. L. Wang, F. Pyczak, L.H. Lou, and R.F. Singer: Mater. Sci. Eng. $A$, 2012, vol. 532, pp. 487-92.

21. N. D'Souza, P.A. Jennings, X.L. Yang, P.D. Lee, M. McLean, and H.B. Dong: Metall. Mater. Trans. B, 2005, vol. 36B, pp. 657-66.

22. J. Coakley, R.C. Reed, J.L.W. Warwick, K.M. Rahman, and D. Dye: Acta Mater., 2012, vol. 60, pp. 2729-38.

23. S. Ma, V. Seetharaman, and B.S. Majumdar: Acta Mater., 2008, vol. 56 , pp. 4102-13.

24. D.M. Collins, N. D’Souza, and C. Panwisawas: Scr. Mater., 2017, vol. 131, pp. 103-07.

25. C. Panwisawas, N. D'Souza, D.M. Collins, and A. Bhowmik: Sci. Rep., 2017, vol. 7, p. 11145.

26. B. Roebuck, D.C. Cox and R.C. Reed: Superalloys 2004, TMS, Warrendale, PA, 2004, pp. 523-28.

27. B. Roebuck, D.C. Cox, and R.C. Reed: Scr. Mater., 2001, vol. 44, pp. $917-21$.

28. S.Y. Huang, K. An, Y. Gao, and A. Suzuki: Metall. Mater. Trans. $A$, 2018, vol. 49A, pp. 740-51.

29. JMatPro: Ni Module (Version 2.0), Sente Software, Guildford, UK, Nov 2002.

30. N. Warnken, D. Ma, M. Mathes, and I. Steinbach: Mater. Sci. Eng. A, 2005, vols. 413-414, pp. 267-71. 